\title{
PENGARUH FAKTOR ORGANISASI TERHADAP MATURITAS BUDAYA KESELAMATAN PASIEN DI RUMAH SAKIT A.M PARIKESIT TENGGARONG TAHUN 2017
}

\section{INFLUENCE OF ORGANIZATION FACTOR TOPATIENT SAFETY CULTURE MATURITY AT A.M PARIKESIT TENGGARONG HOSPITAL 2017}

\author{
Mauritz Silalahi ${ }^{1}$, Fridawaty Rivai ${ }^{2}$, Ridwan Amiruddin ${ }^{3}$ \\ ${ }^{1}$ Bagian Pelayanan, Rumah Sakit Umum Daerah A M Parikesit, Kabupaten Kutai \\ Kartanegara, Kalimantan Timur \\ ${ }^{2}$ Bagian Manajemen Rumah Sakit, Fakultas Kesehatan Masyarakat, UniversitasHasanuddin \\ ${ }^{3}$ Bagian Gugus Penjaminan Mutu, Fakultas Kesehatan Masyarakat, UniversitasHasanuddin
}

Alamat Korespondensi: Mauritz Silalahi, Bidang Pelayanan Medis, R S A M Parikesit, Tenggarong, Kalimantan Timur, Hp: 081334155545,Email: Silalahi_allen@yahoo.com.

\begin{abstract}
Abstrak
Keselamatan pasien di rumah sakit adalah suatu sistem dimana rumah sakit membuat asuhan pasien lebih aman.Penelitian ini bertujuan menganalisis pengaruh kepemimpinan, komunikasi dan kerja tim terhadap maturitas budaya keselamatan pasien di Rumah Sakit A.M Parikesit Tenggarong. Desain penelitian ini menggunakan rancangan survey analitik dengan pendekatan cross sectional study. Penelitian ini dilaksanakan di Rumah Sakit A.M Parikesit Tenggarong. Sampel penelitian ini sebanyak 175 responden yang merupakan staf di rumah sakit. Analisis data menggunakan uji regresi linear untuk melihat pengaruh variabel independen terhadap variabel dependen.Hasil penelitian menunjukkan bahwa ada pengaruh kepemimpinan terhadap maturitas budaya keselamatan pasien $(\mathrm{p}=0.000)$. Ada pengaruh komunikasi terhadap maturitas budaya keselamatan pasien $(\mathrm{p}=0.000)$. Ada pengaruh kerja tim terhadap maturitas budaya keselamatan pasien $(\mathrm{p}=0.000)$. Tingkat maturitas budaya keselamatan pasien berada pada kategori proaktif.
\end{abstract}

Kata Kunci : kepemimpinan, komunikasi, kerja tim, maturitas budaya keselamatan pasien

\begin{abstract}
Patient safety in the hospital is a system where the hospital makes the patient's care safer.This study aims to analyze the influence of leadership, communication and teamwork on the maturity of patient safety culture at A.M Parikesit Tenggarong Hospital. This research design was analytical survey design with cross sectional study approach. This research was conducted at A. Parikshit Tenggarong Hospital. The sample of this study as many as 175 respondents who are staff in the hospital. Data analysis using linear regression test to see the effect of independent variable to dependent variable. The results showed that there was a leadership influence on the maturity of patient safety culture $(p=0.000)$. There is an effect of communication on the maturity of the patient's safety culture $(p=0.000)$. There is an influence of teamwork on the safety maturity of the patient $(p=0.000)$. The level of maturity of patient safety culture is in the proactive category.
\end{abstract}

Keywords: leadership, communication, teamwork, maturity of patient safety culture 


\section{PENDAHULUAN}

Keselamatan pasien merupakan prinsip dasar dari pelayanan kesehatan yang memandang bahwa keselamatan merupakan hak bagi setiap pasien dalam menerima pelayanan kesehatan. Depkes RI (2006) menjadikan hak pasien sebagai standar pertama pada tujuh standar pada tujuh standar keselamatan pasien rumah sakit. World Health Organization (WHO) Collaborating Center for Patient Safety Sollutions bekerja sama dengan Joint Comission and Joint Comission International telah memasukkan masalah keselamatan pasien dengan menerbitkan enam program keselamatan pasien pada 2005 dan sembilan panduan solusi keselamatan pasien di rumah sakit pada tahun 2007 (WHO, 2007).

Fokus terhadap keselamatan pasien ini didorong oleh masih tingginya angka Kejadian Tak Diinginkan (KTD) atau Adverse Event di RS secara global maupun nasional. KTD yang terjadi di berbagai negara diperkirakan sekitar 4.0-16.6\% (Vincent et al., 2002), dan hampir $50 \%$ di antaranya diperkirakan adalah kejadian yang dapat dicegah (Smits et al., 2008). World Health Organization (WHO), 2014. Di Eropa mengalami pasien dengan resiko infeksi $83,5 \%$ dan bukti kesalahan medis menunjukkan 50-72,3\%. Di kumpulkan angka-angka penelitian rumah sakit di berbagai Negara, ditemukan KTD dengan rentang 3,2 - 16,6 \%. Laporan IKP oleh KKP-RS (Komite Keselamatan PasienRumah Sakit) di Indonesia pada bulan Januari-April 2011, menemukan bahwa adanya pelaporan kasus KTD $(14,41 \%)$ dan KNC $(18,53 \%)$ yang disebabkan karena proses atau prosedur klinik $(9,26$ $\%)$, medikasi (9,26\%), dan Pasien jatuh (5,15\%). Raharjo (2006) yang mengutip dari Herkutanto (2005) melaporkan adanya 126 kasus tuduhan malpraktik terhadap rumah sakit selama periode 1999 sampai 2004. Majelis Kode Etik Kedokteran seperti yang dikutip Daud (2005) juga mencatat 41 kasus malpraktek di DKI Jakarta selama Juli - September 2003. Data kejadian pasien jatuh di Indonesia berdasarkan Kongres XII PERSI (2012) melaporkan bahwa kejadian pasien jatuh tercatat sebesar 14\%, padahal untuk mewujudkan keselamatan pasien angka kejadian pasien jatuh seharusnya $0 \%$.

Rumah Sakit Umum Daerah A. M Parikesit Tenggarong merupakan rumah sakit yang memiliki visi "Menjadi Rumah Sakit Umum Daerah Terkemuka yang dikelola secara Profesional". Berdasarkan data sekunder diketahui bahwa insiden keselamatan pasien pada awal tahun 2017 sudah mencapai $25 \%$ dari angka kejadian pada tahun sebelumnya. Besarnya dampak yang dapat timbul akibat insiden keselamatan pasien mengharuskan organisasi pelayanan kesehatan melaksanakan tindakan terkait keselamatan pasien. Hal ini untuk menjamin kualitas perawatan dipertahankan dan perawatan berkualitas diberikan kepada pasien (ssburg, 2002).

Rumah sakit harus menjamin penerapan keselamatan pasien pada pelayanan kesehatan yang diberikannya kepada pasien (Fleming M, 2008). Upaya dalam pelaksanaan keselamatan pasien diawali dengan penerapan budaya keselamatan pasien (KKP-RS, 2008), dengan berfokus pada budaya keselamatan akan menghasilkan penerapan keselamatan pasien yang lebih baik dibandingkan hanya berfokus pada program keselamatan pasien saja (El-Jardali et al., 2011).

Menurut Badan Nasional

Keselamatan Pasien, ada tujuh langkah untuk meningkatkan keselamatan pasien, langkah yang paling penting dalam meningkatkan keselamatan pasien ini adalah dengan mengukur budaya keselamatan pasien yang ada (The Health Foundation, 2011). Salah satu cara mengukur budaya keselamatan pasien adalah dengan mengukur tingkat kematangan budaya keselamatan.

Maturitas atau kematangan budaya keselamatan pasien merupakan tahap perkembangan budaya keselamatan pasien (Fleming, 2000). Survey pendahuluan yang telah dilakukan di RSUD A.M.Parikesit Tenggarong dalam menilai budaya keselamatan disimpulkan bahwa pencapaian RSUD A.M Parikesit 
Tenggarong rata - rata bernilai $50,7 \%$. Membangun kesadaran akan nilai keselamatan pasien, memimpin dan mendukung staf dalam penerapan keselamatan pasien merupakan bagian penting dalam menciptakan budaya keselamatan pasien (Permenkes No. 1691, 2011), dan untuk lebih mengetahui pengaruh organisasi terhadap budaya keselamatan pasien dilakukan penelitian menganalisa pengaruh organisasi/manajemen terhadap maturitas budaya keselamatan pasien di RS A M Parikesit Kabupaten Kutai Kartanegara tahun 2017.

\section{BAHAN DAN METODE \\ Lokasi dan Rancangan penelitian}

Penelitian ini dilakukan di Rumah

Sakit A M Parikesit Tenggarong Kabupaten Kutai Kartanegara. Jenis penelitian yang digunakan adalah penelitian kuantitatif dengan rancangan survei analitik, menggunakan pendekatan cross sectional study.

\section{Populasi dan sampel}

Populasi dalam penelitian ini adalah seluruh staf di seluruh unit pelayanan di RS RSUD A.M Parikesit Tenggarong berjumlah 658 orang. Sampel penelitian ini berjumlah 177 orang. Teknik pengambilan sampel dalam penelitian ini adalah proporsional random sampling yaitu pengambilan sampel yang memperhatikan pertimbangan unsur-unsur atau kategori dalam populasi penelitian.

\section{Metode pengumpulan data}

Instrumen yang digunakan dalam pengambilan data yaitu kuesioner, mengenaivariabel independen yang berupa faktor organisasi yang terdiri atas kuesioner tentang identitas responden, kuesioner tentang kepemimpinan, kuesioner tentang komunikasi dan kuesioner tentang kerja tim sedangkan variabel dependen yaitu maturitas budaya keselamatan pasien.

Pengukuran yang digunakan dalam proses pengolahan data adalah dengan menggunakan skala likert, dimana responden menyatakan tingkat setuju atau tidak setuju mengenai berbagai objek mengenai perilaku obyek, orang, atau kejadian (Sugiono, 2006).

Skala Likert digunakan untuk mengukur sikap, pendapat, dan persepsi seseorang atau sekelompok orang tentang fenomena sosial. Pada penelitian ini responden memilih salah satu dari jawaban yang tersedia, kemudian jawaban diberi skor tertentu. Skor responden yang ditafsirkan sebagai posisi responden dalam skala likert:Sangat Tidak Setuju $($ STS $)=1$, Tidak Setuju $(T S)=2$, Setuju $(S)=3$, dan Sangat Setuju $(\mathrm{SS})=4$

\section{Analisis data}

Teknik analisis data yang digunakan adalah analisis univariat, analisis bivariat dan analisa multivariat. Analisis univariat dilakukan untuk mendapatkan gambaran umum masalah penelitian dengan cara mendeskripsikan tiap-tiap variabel yang digunakan dalam penelitian dan karakteristik dari responden. Analisis bivariat dilakukan untuk melihat hubungan dua variabel yaitu antara variabel independen yaitu faktor organisasi dan variabel dependen yaitu maturitas budaya keselamatan pasien.Analisis multivariatdigunakan untuk melihat pengaruh variabel independen dan variabel dependen dan analisisregresi linear, yakni menganalisis pengaruh variabel faktor organisasi terhadap variabel maturitas budaya keselamatan pasien.

\section{HASIL}

\section{Karakteristik responden}

Tabel 1 diketahui bahwa responden terbanyak adalah yang berjenis kelamin wanita dengan distribusi responden lakilaki sebesar 32,6\% dan perempuan sebesar $67,4 \%$. Dari karakteristik umur responden, responden terbanyak pada rentang usia 25 - 35 tahun sebesar 56,6\%. Berdasarkan tingkat pendidikan responden, responden paling banyak yaitu dengan Pendidikan D3 sebesar $91 \%$. Berdasarkan masa kerja responden, paling banyak responden bekerja pada rentang 1-5 tahun sebesar 40,6\%.

\section{Analisis Univariat}


Tabel2 dijelaskan bahwa meskipun sebagian besar responden memiliki persepsi yang Baik terkait kepemimpinan sebesar 72,6\%, akan tetapi responden dengan persepsi yang kurang baik, persepsi responden terhadap komunikasi sebagian besar responden memiliki persepsi yang Baik sebesar 74,9\%, namun masih tetap ada responden dengan persepsi yang kurang baik sebesar 25,1\%, dan persepsi yang Baik terkait kerja tim dengan jumlah sebesar $52 \%$ responden, akan tetapi responden dengan persepsi yang kurang baik juga masih ada sebesar $48 \%$ dan memiliki persepsi yang Baik terkait maturitas keselamatan pasien yaitu sebesar 51,4\% responden, akan tetapi responden dengan persepsi yang kurang baik juga masih ada sebesar 48,6\% responden. Dari tabel 3, dari hasil persepsi responden maka kategori maturitas keselamatan pasien di RS A.M Parikesit Tenggarong berada pada Kategori Proaktif sebesar 67,4\%.

\section{Tabel 1 : Distribusi Frekuensi Karakteristik Responden Rumah Sakit A.M Parikesit} Tahun 2017

\begin{tabular}{lcc}
\hline Karakteristik Responden & Rumah Sakit A.M Parikesit \\
\hline Jenis Kelamin & n & \% \\
Laki - laki & 57 & 32,6 \\
Perempuan & 118 & 67,4 \\
Umur & & \\
$<25$ tahun & 9 & 5,1 \\
$25-35$ tahun & 99 & 56,6 \\
$36-45$ tahun & 43 & 24,6 \\
$46-50$ tahun & 14 & 8,0 \\
$>50$ tahun & 10 & 5,7 \\
Pendidikan Terakhir & & 24,0 \\
SMA/SMK & 42 & 52,0 \\
D3 & 91 & 18,3 \\
S1/D4 & 32 & 5,7 \\
Profesi & 10 & 40,6 \\
Masa Kerja & & 28,6 \\
1-5 tahun & 71 & 18,9 \\
6-10 tahun & 50 & 12,0 \\
11-20 tahun & 33 & \\
$>$ 20 tahun & 21 & \\
\hline
\end{tabular}

\section{Sumber: Data Primer, 2017}

\section{Analisis Bivariat}

Tabel 4 diketahui bahwa hasil uji korelasi variabel kepemimpinan terhadap maturitas keselamatan pasien menunjukkan nilai signifikansi sebesar $0.000 \quad(\mathrm{p}<0.05)$, dengan demikian disimpulkan bahwa ada hubungan kepemimpinan terhadap maturitas keselamatan pasien dengan nilai $\mathrm{r}(.482)$ yang berarti kekuatannya sedang dan arahnya positif, artinya semakin baik kepemimpinan maka maturitas keselamatan pasien semakin baik, begitupun sebaliknya. Hasil uji korelasi variabel komunikasi terhadap maturitas keselamatan pasien menunjukkan nilai signifikansi sebesar $0.000 \quad(\mathrm{p}<0.05)$, dengan demikian disimpulkan bahwa ada hubungan komunikasi terhadap maturitas keselamatan pasien dengan nilai $r$ (.554) yang berarti kekuatannya sedang dan arahnya positif, artinya semakin baik komunikasi maka maturitas keselamatan 
pasiensemakin baik, begitupun sebaliknya. Hasil uji korelasi kerja tim terhadap maturitas keselamatan pasien menunjukkan nilai signifikansi sebesar $0.000 \quad(\mathrm{p}<0.05)$, dengan demikian disimpulkan bahwa ada hubungan kerja tim terhadap maturitas keselamatan pasien dengan nilai $\mathrm{r}$ (.558) yang berarti kekuatannya sedang dan arahnya positif, artinya semakin baik kerja tim maka maturitas keselamatan pasien semakin baik, begitupun sebaliknya.

Tabel 2 :Persepsi Responden Terhadap Kepemimpinan, komunikasi dan kerja tim di RS A.M Parikesit Tenggarong Tahun 2017

\begin{tabular}{lcc}
\hline Organisasi & Frekuensi (n) & Persentase (\%) \\
\hline Kepemimpinan & & \\
Kurang Baik & 48 & 27,4 \\
Baik & 127 & 72,6 \\
Total & 175 & 100 \\
Komunikasi & & \\
Baik & 44 & 25,1 \\
Kurang Baik & 131 & 74,9 \\
Total & 175 & 100 \\
Kerja Tim & & \\
Baik & 84 & 48 \\
Kurang baik & 91 & 52 \\
Total & 175 & 100 \\
\hline Sumber
\end{tabular}

Sumber : Data Primer, 2017.

Tabel 3 : Distribusi Jawaban Responden Berdasarkan Pernyataan Tentang Variabel Maturitas Keselamatan Pasiendi RS A.M Parikesit Tenggarong Tahun 2017

\begin{tabular}{lcc}
\hline Kategori Maturitas Keselamatan & Frekuensi (n) & Persentase (\%) \\
Pasien & & 0 \\
\hline Patologis & 0 & 0 \\
Reaktif & 0 & 30,9 \\
Kalkulatif & 54 & 67,4 \\
Proaktif & 118 & 1,7 \\
Generatif & 3 & \\
\hline
\end{tabular}

Sumber : Data Primer, 2017.

\section{Analisis Multivariat}

Tabel 5 diketahui bahwa hasil uji pengaruh kepemimpinan terhadap maturitas keselamatan pasien menunjukkan nilai signifikansi sebesar $0.000 \quad(\mathrm{p}<0.05), \quad$ sehingga dapat disimpulkan bahwa ada pengaruh kepemimpinan terhadap maturitas keselamatan pasien.Hasil uji pengaruh komunikasi terhadap maturitas keselamatan pasien menunjukkan nilai signifikansi sebesar $0.000 \quad(\mathrm{p}<0.05)$, sehingga dapat disimpulkan bahwa ada pengaruh komunikasi terhadap maturitas keselamatan pasien. Hasil uji pengaruh kerja tim terhadap maturitas keselamatan pasien menunjukkan nilai signifikansi sebesar $0.000 \quad(p<0.05)$, sehingga dapat disimpulkan bahwa ada pengaruh kerja tim terhadap maturitas keselamatan pasien. 
Tabel 5 : Pengaruh Kepemimpinan, Komunikasi, Kerja Tim terhadap Maturitas Keselamatan Pasien pada Rumah Sakit A.M Parikesit Tahun 2017

\begin{tabular}{|c|c|c|c|c|c|c|}
\hline \multirow[t]{2}{*}{ No } & \multirow[t]{2}{*}{ Model } & \multicolumn{2}{|c|}{$\begin{array}{l}\text { Unstandardized } \\
\text { Coefficients }\end{array}$} & \multirow{2}{*}{$\begin{array}{l}\text { Standardized } \\
\text { Coefficients } \\
\text { Beta }\end{array}$} & \multirow[t]{2}{*}{$\mathbf{t}$} & \multirow[t]{2}{*}{ Sig. } \\
\hline & & B & Std. Error & & & \\
\hline & (Constant) & 41.472 & 5.918 & & 7.008 & .000 \\
\hline 1 & Kepemimpinan & .924 & .184 & .305 & 5.034 & .000 \\
\hline 2 & Komunikasi & 1.022 & .247 & .290 & 4.144 & .000 \\
\hline 3 & Kerja Tim & 1.483 & .331 & .297 & 4.479 & .000 \\
\hline
\end{tabular}

Sumber : Data Primer, 2017.

\section{PEMBAHASAN}

Berdasarkan hasil analisis mengenai maturitas budaya keselamatan pasien di RSUD AM Parikesit Tenggarong ini berada di tingkat proaktif. Hasil ini ditetapkan berdasarkan jawaban responden dengan persentase tertinggi. Pada umumnya karakteristik tentang kondisi maturitas budaya keselamatan pasien yang berada pada tingkat ini yaitu keadaan dimana terdapat pendekatan komprehensif terhadap budaya patient safety, intervensi yang evidence-based sudah diimplementasikan. Beberapa faktor juga telah diidentifikasi sebagai pendukung pengembangan budaya keselamatan pasien. Kunci di antaranya adalah pimpinan/manajer, supervisor langsung, faktor perilaku perorangan, sistem pelaporan, peraturan dan prosedur dan subkultur organisasi perawatan kesehatan (Clarke 1999, Cooper 2000, Glendon \& Stanton 2000, Coohen et al., 2003).

Berdasarkan hasil uji hipotesis, ditemukan bahwa ada pengaruh kepemimpinan dengan maturitas budaya keselamatan pasien, adanya pengarahan, supervisi dan koordinasi dari pimpinan hal tersebut mempengaruhi tingkat maturitas budaya keselamatan. Dari sisi pengarahan, terlihat dari wadir pelayanan dapat mendelagasikan wewenang dengan baik kepada bawahannya terkait penerapan patient safety kemudian wadir pelayanan juga memberikan sanksi yang tegas terhadap kesalahan yang dilakukan oleh karyawan terkait penerapan patient safety, meskipun dari sisi penghargaan terhadap karyawan yang memiliki kinerja baik dalam meningkatkan program patient safety masih belum begitu maksimal.

Hasil uji pengaruh kepemimpinan terhadap maturitas budaya keselamatan pasien menunjukkan bahwa terdapat pengaruh yang signifikan dari variabel kepemimpinan terhadap maturitas budaya keselamatan pasien di RSUD AM Parikesit Tenggarong ( $\mathrm{p} 0.000<0.05$ ).

Hasil penelitian ini sesuai dengan yang dinyatakan oleh Mallouli et al (2017), studinya ini memberikan penilaian menyeluruh terhadap persepsi keselamatan di antara staf rumah sakit di institusi publik dan swasta. Dalam merekomendasikan penerapan PSC yang kuat dan proaktif di unit OR yang dibutuhkan ialah komitmen kepemimpinan dan dorongan kerja sama tim. Dengan demikian, persepsi praktisi perawatan kesehatan sebagai pemain kunci dalam meningkatkan kualitas keselamatan dan kesehatan. Selain itu hasil penelitian Weaver, dkk (2013) juga menegaskan bahwa tinjauan sistematis baru-baru ini telah membuktikan bahwa dukungan kepemimpinan dan manajerial serta struktur tata kelola dapat berdampak pada budaya keselamatan pasien. Promosi budaya keselamatan pasien dapat di konseptualisasikan dengan sebaik mungkin hanya dengan suatu tatanan yang dapat memberikan intervensi secara tepat untuk melakukan perubahan. Tatanan tersebut antara lain kepemimpinan, kerja tim dan perilaku bukan melalui pendekatan terhadap program atau teknologi tertentu.

Berdasarkan hasil uji hipotesis, ditemukan bahwa ada pengaruh komunikasi dengan maturitas budaya keselamatan pasien, adanya kepercayaan dan keterbukaan, informasi, pentingnya 
keselamatan pasien dan perhatian pengenalan pentingnya keselamatan. Dari sisi kepercayaan dan keterbukaan pegawai mendapat umpan balik positif apabila ada suatu kejadian yang dilaporkan, saling memperingatkan apabila dapat mencam keselamatan pasien. Pada sisi informasi, pegawai bebas menyatakan pendapat dan memberi usulan, informasi pasien selalu tersedia. Pada sisi arti penting keselamatan pasien, setiap masalah yang terjadi selalu didiskusikan bersama dan dicari jalan keluarnya dan mencegah terjadinya kejadian yang tidak diinginkan. Dalam hal perhatian dan pengenalan pentingnya keselamatan, staf diberik kesempatan untuk bertanya apabila ada sesuatu yang berjalan tidak semestinya dan saat operan tidak terjadi masalah.

Hasil uji pengaruh komunikasi terhadap maturitas budaya keselamatan pasien menunjukkan bahwa terdapat pengaruh yang signifikan dari variabel komunikasi terhadap maturitas budaya keselamatan pasien di RSUD AM Parikesit Tenggarong ( $p 0.000<0.05)$.

Hasil penelitian ini sejalan dengan penelitian yang telah dilakukan oleh Ballangrud et al. (2012) yang menjelaskan bahwa dalam penelitian nya, mereka menemukan komunikasi tentang kesalahan dan kerja sama tim dalam unit adalah prediktor yang signifikan terhadap peningkatan frekuensi kejadian yang dilaporkan oleh perawat, dan hasil ini juga serupa dengan penelitian sebelumnya. Keselamatan pasien dan meningkatkan frekuensi kejadian sentinel. Temuan lain dari studi saat ini sesuai dengan penelitian lain, yang menunjukkan bahwa harapan dan tindakan manajer, umpan balik dan komunikasi tentang kesalahan, kerja sama tim di seluruh unit rumah. Selain itu, untuk meningkatka Keselamatan pasien dan meningkatkan frekuensi kejadian sentinel. Temuan lain dari studi saat ini sesuai dengan penelitian lain, yang menunjukkan bahwa harapan dan tindakan manajer, umpan balik dan komunikasi tentang kesalahan, kerja sama tim di seluruh unit rumah sakit.
Hasil analisis deskriptif pada penelitian ini menunjukkan bahwa responden menyatakan bahwa komunikasi di RSUD AM Parikesit termasuk dalam kategori yang baik dan berada pada tingkat maturitas budaya keselamatan pasien yang proaktif. Hal ini menunjukkan bahwa di rumah sakit ini, komunikasi sudah berjalan baik dan seiring hal tersebut tingkat maturitas budaya keselamatan pasien juga sudah baik yang berada pada kategori proaktif.

Berdasarkan hasil uji hipotesis, ditemukan bahwa ada pengaruh kerja tim dengan maturitas budaya keselamatan pasien, adanya komitmen yakni staf berkomitmen mendukung meningkatkan program keselamatan pasien. Adanya komunikasi ide dan gagasan yakni pimpinan selalu ikut berkontribusi terhadap peningkatan program patient safety. Adanya efektivitas interpersonal yakni kemampuan koordinasi para staf untuk mewujudkan pelayanan pasien yang sesuai dengan prosedur patient safety

Hasil uji pengaruh kerja tim terhadap maturitas budaya keselamatan pasien menunjukkan bahwa terdapat pengaruh yang signifikan dari variabel kerja tim terhadap maturitas budaya keselamatan pasien di RSUD AM Parikesit Tenggarong ( $\mathrm{p} 0.000<0.05$ ).

Temuan lain dari beberapa penelitian saat ini yang sesuai dengan hasil tersebut menunjukkan bahwa harapan dan tindakan manajer, umpan balik dan komunikasi tentang kesalahan, kerja sama tim di seluruh unit rumah sakit (Alamadi 2010; Ballangrud et al 2012), penggantian dan transisi yang terjadi di rumah sakit (ElJardali et al 2011) adalah prediktor persepsi keseluruhan budaya keselamatan pasien.

Hasil analisis deskriptif pada penelitian ini menunjukkan bahwa responden menyatakan bahwa komunikasi di RSUD AM Parikesit termasuk dalam kategori yang baik sebesar $74,9 \%$ dan berada pada tingkat maturitas budaya keselamatan pasien yang proaktif. Hal ini menunjukkan bahwa di rumah sakit ini, komunikasi sudah berjalan baik dan 
maturitas budaya keselamatan pasien masih dalam tingkat yang proaktif. Dapat disimpulkan bahwa, salah satu penyebab hal ini terjadi ialah dikarenakan sistem masih bersifat fragmentasi, dikembangkan hanya pada saat akreditasi dan respon hanya saat terjadinya insiden terkait keselamatan pasien. Sehingga sangat perlu meningkatkan proses yang fokus dalam mempertahankan keselamatan pasien.

Hasil analisis deskriptif pada penelitian ini menunjukkan bahwa responden menyatakan bahwa kerja tim di RSUD AM Parikesit termasuk dalam kategori yang baik dan berada pada tingkat maturitas budaya keselamatan pasien yang proaktif. Hal ini menunjukkan bahwa di rumah sakit ini, kerja tim sudah berjalan dengan cukup baik dan maturitas budaya keselamatan pasien juga seiring yang berada pada kategori proaktif.

\section{KESIMPULAN DAN SARAN}

Berdasarkan penelitian mengenai analisis faktor yang mempengaruhi maturitas budaya keselamatan pasien pada tenaga medis dan paramedis di RSUD AM Parikesit Tenggarong Tahun 2017,peneliti merumuskan kesimpulan sebagai berikut:Adapengaruh kepemimpinan terhadap maturitas budaya keselamatan pasien pada tenaga medis dan paramedis di RSUD AM Parikesit Tenggarong Tahun 2017, ada pengaruh komunikasi terhadap maturitas budaya keselamatan pasien pada tenaga medis dan paramedis di RSUD AM Parikesit Tenggarong Tahun 2017 dan ada pengaruh kerja tim terhadap maturitas budaya keselamatan pasien pada tenaga medis dan paramedis di RSUD AM Parikesit Tenggarong Tahun 2017.

Berdasarkan hasil penelitian dan kesimpulan yang telah dirumuskan, maka dikemukakan beberapa saran atau rekomendasi sebagai berikut, yaitu kepada pihak manajemen RSUD AM Parikesit, agar tetap memperhatikan memperhatikan komponen kepemimpinan, komunikasi dan kerja tim agar dapat mempertahankan dan meningkatkan maturitas budaya keselamatan pasien. Terdapat beberapa rekomendasi upaya yang dapat dilakukan antara lain meningkatkan peran kepemimpinan dalam hal memberikan pengarahan, supervisi dan koordinasi. Selain itu, proses komunikasi dapat diefektifkan lagi. Serta kerja tim dapat didukung dengan meningkatkan proses komunikasi antar individu/unit, kordinasi dan kohesivitas tim.Maturitas budaya keselamatan pasien di RSUD AM Parikesit Tenggarong sudah dinilai baik. Maturitas budaya keselamatan berada pada tingkat Proaktif tetapi masih terdapat indikatorindikator yang belum optimal. Untuk kedepannya, agar pihak rumah sakit meningkatkan lagi indikator - indikator tersebut sehingga maturitas budaya keselamatan pasien berada pada tingkat yang ingin dicapai.

\section{DAFTAR PUSTAKA}

Alamadi et al, (2010). Assesment of Patient Safety Culture in Saudi Arabian hospitals, Qual Saf Health Care.

angrud et al, (2012). Nurse' perception of patient safety climate in intensive care unit, A Cross Sectional Study

Cooper M. (2000). Towards a model of safety culture. Safety Science, 36, 111-136.

Coohen et al (2003). Changing the Culture of Patient Safety; Leadership's Role in Health Care Quality Improvement, Research Gate.

Clarke S, (2000). Safety culture : underspesific and overrated ? International Journal of Management Reviews, vol 2, pg 65-90

El-Jardali, F., Dimassi, H., Jamal, D., Jaafar, M., \& Hemadeh, N. (2011).

Predictors and outcomes

of patient safety culture in hospitals. BMC Health Services Research, 11:45- 45.

Flemming, Mark. (2000). Patient Safety Culture: Sharing and Learning From Each Other.

Flemming, Mark. (2005). Patient safety culture measurement: a "how to" guide. Healthcare Quarterly Vol 8: 14-19. 
Fleming, M. (2008). Patient Safety Culcure Improvement tool: Development \& Guidelines for use. Healthcare Quzrterly. 11: 10-15.

Glandon I \& Stanton (20000, Perspective on Safety Culture, Safety Science 34, pg 193-214

Health Foundation (2011), Leading Health Care Transformation: A Primer for Clinical Leaders, CRC Press Taylor and Francis Group.

Joint Commission International. (2006). Patient safety, essentials for healthcare.(International Edition). USA:

Kementerian Kesehatan. (2011). Permenkes RI Nomor 1691 Menkes Tentang Keselamatan Pasien Rumah Sakit

Kohn et al. (2000). To err is human: Building a safer health system. Committee on quality of health care in America. IOM. National Academy of Science

Komite Keselamatan Pasien Rumah Sakit (2008). Pedoman Pelaporan Insiden Keselamatan Pasien. Jakarta: KKPRS.

Mallouli et al, (2017), Assesing Patient Safety Culture in Tunisian Operating rooms, a multicenter study, Int J Qualt Health Care, pg. $176-179$

Smith et al, (2008), he psychometric properties of the 'Hospital Survey on Patient Safety Culture' in Dutch hospitals, BMC Health Services Research.

Sugiyono, (2006), Statistika untuk Penelitian, cetakan kesepuluh, CV Alfabeta Bandung.

Swansburg (2002), Introduction to management and leadership for nurse manager, $3^{\text {rd }}$ edition, Jones and Bartlet Publisher International

Vincent. (2005). Patient safety, What about Patient, MBJ Journals, Qual Saf Health Care 2002;11:76-80.

Weaver J S. et al (2013), Promoting a Culture of Safety as aPatient Safety Strategy; Systemtic Review, Annal of Internal Medicine.
WHO. (2007). WHO Collaborating center for patient safety. Joint Comission and Joint Comission International Solutions. 